\title{
Desvelando a violência no cotidiano das pessoas com deficiência que vivem no rural:
} (in) visibilidade, aproximações e desafios

Unveiling violence in the daily lives of people with disabilities living in rural areas: (in) visibility, approaches and challenges

Revelar la violencia en la vida cotidiana de las personas con discapacidad que viven en zonas rurales: (in) visibilidad, enfoques y desafíos

\section{Resumo}

Objetivo: Relatar as experiências de estudantes de graduação em enfermagem vivenciadas durante a coleta de dados de projeto que buscou conhecer as situações de violência no cotidiano das pessoas com deficiência que vivem no contexto rural. Metodologia: Estudo descritivo do tipo relato de experiência, desenvolvido a partir de uma pesquisa qualitativa realizada por meio de entrevistas semiestruturadas com pessoas com deficiência ou seus cuidadores principais, no caso de menores de 18 anos ou de pessoas com deficiência intelectual. A coleta de dados do projeto que subsidiou este relato ocorreu no período de julho de 2018 a agosto de 2019. Resultados: A experiência permitiu desvelar os desafios vivenciados pelas pessoas com deficiência que vivem em cenário rural e suas famílias no que se refere às dificuldades financeiras, distância geográfica e acesso aos serviços. Ainda, permitiu identificar as diferentes formas de violência vivenciadas pelas pessoas com deficiência como a violência física, sexual, psicológica e a exclusão social. Conclusão: A experiência de desenvolver um estudo com pessoas com deficiência no contexto rural possibilitou a compreensão da magnitude do fenômeno da violência e permitiu a percepção da relevância de estudar seus impactos junto a diferentes populações e cenários. Ainda, trouxe à tona a urgência de um olhar diferenciado no que tange as pessoas com deficiência que vivem neste contexto singular no sentido de proporcionar a atenção integral a saúde dessa população.

Palavras-chave: Violência; Pessoas com deficiência; Saúde da população rural.

\footnotetext{
Abstract

Objective: To report the experiences of undergraduate nursing students experienced during the collection of project data that sought to know the situations of violence in the daily lives of people with disabilities who live in the rural context. Methodology: Descriptive study of the experience report type, developed from a qualitative research carried out through semistructured interviews with people with disabilities or their main caregivers, in the case of minors under 18 years old or people with intellectual disabilities. The data collection of the project that supported this report took place from July 2018 to August 2019. Results: The experience allowed us to unveil the challenges experienced by people with disabilities who live in rural settings and their families with regard to financial difficulties, geographical distance and access to services. It also allowed the
} 
identification of different forms of violence experienced by people with disabilities, such as physical, sexual, psychological violence and social exclusion. Conclusion: The experience of developing a study with people with disabilities in the rural context made it possible to understand the magnitude of the phenomenon of violence and allowed the perception of the relevance of studying its impacts with different populations and scenarios. Still, it brought to the fore the urgency of a different look regarding people with disabilities who live in this unique context in order to provide comprehensive health care to this population.

Keywords: Violence; Disabled persons; Rural health.

\section{Resumen}

Objetivo: Informar las experiencias de estudiantes de enfermería de pregrado vividas durante la recolección de datos del proyecto que buscaba conocer las situaciones de violencia en la vida cotidiana de las personas con discapacidad que viven en el contexto rural. Metodología: Estudio descriptivo del tipo relato de experiencia, desarrollado a partir de una investigación cualitativa realizada a través de entrevistas semiestructuradas con personas con discapacidad o sus principales cuidadores, en el caso de menores de 18 años o personas con discapacidad intelectual. La recolección de datos del proyecto que sustenta este informe se llevó a cabo entre julio de 2018 y agosto de 2019. Resultados: La experiencia permitió conocer los desafíos que experimentan las personas con discapacidad que viven en entornos rurales y sus familias en cuanto a dificultades económicas, distancia geográfica y acceso a servicios. También permitió identificar las diferentes formas de violencia que experimentan las personas con discapacidad, como la violencia física, sexual, psicológica y la exclusión social. Conclusión: La experiencia de desarrollar un estudio con personas con discapacidad en el contexto rural permitió comprender la magnitud del fenómeno de la violencia y permitió percibir la relevancia de estudiar sus impactos con diferentes poblaciones y escenarios. Aún así, puso en evidencia la urgencia de una mirada diferente a las personas con discapacidad que viven en este contexto único para brindar una atención integral de salud a esta población.

Palabras clave: Violencia; Personas con discapacidad; Salud rural.

\section{Introdução}

A violência tornou-se um fenômeno de alta relevância e prevalência mundialmente, inclusive no Brasil. Esta problemática afeta a saúde de indivíduos, famílias e coletividades. É responsável por óbitos, lesões e traumas de natureza física e mental. Seu crescimento remete a reflexões de que o país vive uma nova epidemia social e passa por um dos mais difíceis problemas de saúde pública, impondo desafios para o atendimento nos serviços de saúde. Tais argumentos são fomentados pelos números totais e taxas de óbito das variadas tipologias de violência e na inserção desse fenômeno na sociedade, que determina a qualidade de vida e a saúde da população (Minayo, Souza, Silva, \& Assis, 2018).

A Organização Mundial da Saúde define a violência como o uso de força física ou poder, sob a forma de ameaça ou prática, contra si mesmo, outra pessoa, grupo ou comunidade, que origine ou possa originar sofrimento, morte, dano psicológico, desenvolvimento prejudicado ou privação (World Health Organization [WHO], 2002). A violência atinge diferentes populações, mas acaba tornando mais vulneráveis alguns grupos específicos, a exemplo das mulheres, crianças, idosos e pessoas com deficiência (PcD). Considera-se PcD aquela que possui algum impedimento seja físico, mental, intelectual ou sensorial que, em associação a diferentes barreiras, pode dificultar a participação plena e efetiva das pessoas na sociedade (Brasil, 2009).

O Relatório Mundial sobre deficiência destaca que as PcD tem maior risco de vivenciar situações de violência do que aquelas que não possuem deficiência (WHO, 2011; Dammeyer, \& Chapman, 2018). Posto isso, torna-se relevante desenvolver estudos que identifiquem situações de violências vivenciadas por PcD, sobretudo as que vivem em contextos de maior vulnerabilidade, como o contexto rural.

Este contexto reproduz situações de exclusão, tornando as PcD mais vulneráveis em decorrência de suas características físicas e/ou intelectuais aliadas às particularidades do cenário rural (Tonini \& Lopes, 2017). No cenário rural, o distanciamento em relação aos serviços de saúde, as condições das estradas, a ausência de transporte, a falta de recursos e a demora nos atendimentos as PcD limitam suas possibilidades de acesso aos serviços de saúde, tornando-se um desafio para a integralidade do cuidado a esta população (Ursine, Pereira, \& Carneiro, 2018).

Diante do exposto, esse artigo tem por objetivo relatar as experiências de estudantes de graduação em enfermagem 
vivenciadas durante a coleta de dados de projeto que buscou conhecer as situações de violência no cotidiano das PcD que vivem no contexto rural.

A relevância desse relato se justifica pela necessidade de dar visibilidade aos desafios e possibilidades de desenvolvimento de pesquisas com PcD, em especial, no cenário rural. Ademais, se justifica pela escassez de produção científica sobre o cotidiano de vida das PCD inseridas em áreas rurais, bem como pela importância de estudos que busquem mostrar as tipologias de violência vivenciadas por essa população residente em um cenário singular a fim de buscar estratégias para o enfrentamento de tal problemática e atenção das PcD nestes cenários.

\section{Metodologia}

Trata-se de um estudo descritivo do tipo relato de experiência baseado nas vivências de acadêmicas de enfermagem no processo de geração de dados do estudo intitulado "Determinantes sociais de saúde em pessoas com deficiência, famílias e rede de apoio no cenário rural: múltiplas vulnerabilidades", financiado pelo Programa de Pesquisa para o SUS. Neste projeto buscou-se conhecer além das situações de violência, os demais aspectos que permeiam o cotidiano das PcD e de suas famílias relacionados à saúde, escolaridade, acesso, acessibilidade, condições de saneamento básico, uso de substâncias, emprego e renda.

O estudo de referência para este relato seguiu os pressupostos expressos na Resolução do Conselho Nacional de Saúde $\mathrm{n}^{\circ}$. 466 de 12 de dezembro de 2012 que regulamenta as questões éticas para o desenvolvimento de pesquisa envolvendo seres humanos. Assim, anteriormente a coleta de dados foi obtida aprovação pelo Comitê de Ética em Pesquisa com Seres Humanos da Universidade Federal de Santa Maria, com parecer favorável.

Os dados da pesquisa foram gerados por meio de entrevistas semiestruturadas desenvolvidas no período de julho de 2018 a agosto de 2019. O cenário de coleta de dados foi composto por oito municípios pertencentes às regiões norte e noroeste do estado do Rio Grande do Sul, Brasil. Incluíram-se tais municípios pelo fato de que nestes a população rural era maior que a população urbana. Do total de municípios, apenas quatro possuíam unidades de Estratégia Saúde da Família no cenário rural. Nestas, os atendimentos eram realizados apenas em um dia da semana.

Participaram do estudo 276 pessoas, dentre eles, as PcD ou seus cuidadores principais, no caso de menores de 18 anos ou de pessoas com deficiência intelectual. Foram incluídas PcD física congênita, física adquirida, visual congênita, auditiva congênita, intelectual e múltipla. Não foram elencados critérios de exclusão.

Das 276 PcD, 59\% eram homens e $41 \%$ mulheres. Quanto ao tipo de deficiência, 48,2\% possuíam deficiência intelectual; 19,9\% possuíam deficiência física adquirida; $14,1 \%$ deficiência física congênita; 9,8\% deficiência múltipla; 6,2\% deficiência auditiva congênita; e 1,8\% deficiência visual congênita. No que se refere à faixa etária, 55\% possuem mais de 40 anos; $20 \%$ eram idosos e $13 \%$ eram crianças ou adolescentes. Em relação à escolaridade, $86 \%$ nunca estudaram ou possuíam ensino fundamental incompleto. Quanto ao acesso aos serviços de saúde, $96 \%$ faziam uso exclusivo do Sistema único de Saúde. O acesso ao transporte público regular foi relatado por $47 \%$ das $\mathrm{PcD}$, das quais $77,2 \%$ informaram que este não possuía condições de acessibilidade. Em relação à inserção no mercado de trabalho, 56\% relataram que trabalhavam, e destas $95 \%$ atuando em área rural, recebendo até um salário mínimo. Do total, 47,2\% referiram receber o Benefício de Prestação Continuada (BPC).

A equipe de pesquisadores foi composta por discentes e docentes do curso de graduação em enfermagem, vinculados ao Núcleo de Estudo e Pesquisa em Saúde Coletiva da Universidade Federal de Santa Maria (NEPESC/UFSM, campus Palmeira das Missões).

Para a coleta dos dados, realizou-se o levantamento do número de PcD residentes na área rural dos municípios cenário da pesquisa com auxílio principalmente dos Agentes Comunitários de Saúde. Após, fez-se contato com os gestores dos 
municípios para verificar a disponibilidade dos ACS para que as equipes de pesquisadores se deslocassem até as áreas rurais. Durante o levantamento do número de PcDs, a equipe de pesquisadores constituía-se por duas docentes responsáveis e quatro acadêmicas. Durante o período de coleta de dados a equipe se dividia em duas duplas de acadêmicas que se deslocavam para as áreas rurais em dois veículos juntamente com os ACS pertencentes a cada micro área.

Ao chegar às residências, eram explicitados o objetivo da pesquisa e seus procedimentos metodológicos mediante leitura do Termo de Consentimento Livre e Esclarecido. Assegurava-se que a participação na pesquisa era optativa e que poderia ser interrompida a qualquer momento caso o participante desejasse. Para tanto, a equipe realizava a leitura de forma calma e pausada, bem como utilizava uma linguagem simples e compreensível.

Quando a PcD aceitava participar do estudo, solicitava-se que a mesma ficasse sozinha com os pesquisadores. Assim, os ACS e familiares não permaneciam no mesmo ambiente no momento da coleta de dados, reduzindo os possíveis vieses e assegurando os princípios éticos de pesquisa. Pontua-se que nos casos de pessoas com deficiência intelectual ou menores de 18 anos, a pesquisa era respondida pelo cuidador principal, com exceção das perguntas relacionadas à violência, que neste caso, não eram realizadas.

\section{Resultados e Discussão}

\subsection{Vivências, experiências e desafios da caminhada}

Durante a aproximação com as famílias as demonstrações de carinho, afeto e interesse em participar da pesquisa e contribuir fizeram parte das falas. Grande parte dos entrevistados foram muito acolhedores e participativos, o que possibilitou que as acadêmicas se sentissem a vontade para desenvolver as entrevistas. Foi possível perceber que as famílias que residem no cenário rural sentem a necessidade de serem ouvidas e ser foco de atenção. Assim, participar da pesquisa ao mesmo tempo em que permitiu gerar dados, também constituiu um espaço de escuta para as PcD e suas famílias que verbalizaram seus anseios, dificuldades e vivências cotidianas.

O contexto estudado era localizado em áreas dispersas, com grandes extensões territoriais rurais, sendo necessário percorrer longas distâncias de estradas de chão, visto que algumas famílias moravam a mais de trinta quilômetros das áreas urbanas, onde a maioria das unidades de saúde se localizavam. Para acessar o domicílio dos participantes, muitas vezes a equipe de coleta de dados precisava caminhar, pois o local não permitia o acesso de veículos, havendo estradas precárias com muitas pedras e até córregos que impediam a chegada até as casas. Ao passar por essas situações, a equipe vivenciou na prática as dificuldades de acesso dessa população, já que para chegar a qualquer serviço precisam passar por esses mesmos caminhos.

Além das condições precárias das estradas, é necessário pontuar que a maioria das famílias não possuía veículo próprio, assim como o transporte público era escasso. Deste modo, o deslocamento até o meio urbano era extremamente difícil e limitado, realizado geralmente uma vez ao mês para a realização de atividades essenciais, como ir ao mercado, farmácia e serviços de saúde. O que culminava no isolamento social e impedia que as PcD se inserissem plenamente na sociedade. Havia ainda, diversos relatos de pessoas que gostariam de estudar e trabalhar, mas não tinham a oportunidade, pois além de morarem em um município de porte pequeno, residiam em áreas rurais.

Especificamente em relação ao acesso aos serviços de saúde, a literatura descreve as dificuldades vivenciadas pela população de áreas rurais para obter cuidados de saúde (Mangundu, Roets, \& van Rensberg, 2020; Douthit, Kiv, Dwolatzky, \& Biswas, 2015), incluindo, dentre outros fatores, as longas distâncias em relação às áreas urbanas e custos inacessíveis com transporte (Mangundu et al., 2020), além de transporte público insuficiente (Douthit et al., 2015).

Diante disso, fica explícito que o acesso aos fatores que determinam e condicionam a saúde como alimentação, moradia, trabalho, renda, educação, transporte, lazer, bens e serviços essenciais a exemplo da saúde (Brasil, 1990) não se dá de 
forma igualitária entre as áreas urbana e rural. Com isso, há uma desigualdade de direitos as populações dessas áreas, mesmo a Constituição Federal Brasileira prevendo direitos iguais (Brasil, 1988).

Ao adentrar os domicílios dos participantes identificou-se que o seu cotidiano era marcado pela vulnerabilidade mediante condições econômicas e de saneamento básico desfavoráveis, bem como a baixa escolaridade. Muitos domicílios eram de madeira, tinham chão batido e não possuíam energia elétrica. $\mathrm{O}$ acesso a telefone era precário e nenhuma residência possuía internet. As famílias das PcD relataram também que por falta de recursos financeiros não possuíam roupas adequadas para ir à escola e participar de atividades comunitárias, gerando vergonha, angústia e constrangimento tanto nos familiares como nas PcD e com isso, as privando da participação na comunidade. Diante disso, é notório que as PcD enfrentam inúmeros obstáculos ao longo da vida como maiores taxas de pobreza, desemprego e situações de exclusão social (WHO, 2011).

As famílias eram proprietárias de pequenas extensões territoriais e viviam basicamente dos recursos proporcionados pela agricultura com cultivo de grãos e frutas, bem como a criação de vacas leiteiras. Apesar de sua importância para a subsistência das famílias, a renda gerada não atendia as suas necessidades. Nesta perspectiva, o recurso financeiro advindo do BPC mostrava-se imprescindível.

O BPC se trata de um benefício da assistência social garantido constitucionalmente e regulamentado pela Lei $\mathrm{n}^{\circ}$ 8.742/93 (Lei Orgânica da Assistência Social) e implantado efetivamente em janeiro de 1996. É destinado a pessoas idosas acima de 65 anos e a PcD e equivale a um salário mínimo (Brasil, 1993; Brasil, 1999). Percebe-se que paulatinamente as PcDs vem sendo tratadas como cidadãos com direitos a serem defendidos e efetivados (Souza \& Ireland, 2020), como o BPC. No entanto, ainda existem muitos desafios a serem superados para efetivar de forma concreta todos os direitos dessa população.

Diante de todas as vulnerabilidades inseridas no cotidiano das PcD e de suas famílias, a equipe de pesquisa via-se impotente. Havia o desejo de melhorar as condições de vida e saúde dessas pessoas e ofertá-las os direitos que todos os cidadãos deveriam ter, independente da área na qual residam. A vulnerabilidade a que estão sujeitos revela a necessidade de um olhar diferenciado no que tange aos direitos humanos das PcD atentando para a máxima de que todos, independentemente do cenário em que residem devem ter acesso a bens, serviços e direitos.

Ir a campo para a coleta de dados possibilitou desvelar uma realidade vivida todos os dias pelas PcD e suas famílias que residem no contexto rural. Apesar dos desafios encontrados pela equipe de pesquisa, muitos dos quais são compartilhadas pelos participantes, realizar o estudo no cenário rural foi essencial para dar visibilidade às particularidades culturais, sociais, geográficas e econômicas deste cenário. Ademais, considerando que a maioria dos estudos com PcD são desenvolvidos no cenário urbano, esse relato se reveste de importância ainda maior, mostrando as vivências e dificuldades cotidianas dessas pessoas e de suas famílias in loco.

\subsection{Violências vivenciadas pelas PCD no cenário rural e o papel dos profissionais da saúde}

O conceito de violência é complexo e multifacetado. A violência manifesta-se sob variadas formas, estando relacionada à força, ao impulso, ao comportamento intencional que gera prejuízos de natureza física como ferimentos, tortura, morte, e de natureza psíquica como humilhações, ameaças e ofensas (Paviani, 2016). Considerando o cenário rural, a violência se exacerba pelas singularidades desse contexto e localização em relação às áreas urbanas (Costa, \& Lopes, 2012). Diante disso, as vítimas de violência que residem no cenário rural tem dificuldades para acessar os serviços de atendimento que estão localizados, majoritariamente, no espaço urbano, tornando ainda mais invisível esta problemática (Arboit, Costa, Silva, Colomé, \& Prestes, 2018).

Se a violência no cenário rural por si só já é uma problemática considerada grave e invisível, quando esta se direciona as pessoas com deficiência residentes neste cenário, a situação é ainda pior. Isso porque muitas vezes as pessoas com deficiência são incapazes de se defender/proteger contra os atos violentos devido a limitações físicas e/ou psíquicas. 
A violência contra as PcD afeta seus direitos humanos, é perpetrada dentro e fora das famílias e possui a capacidade de comprometer a qualidade de vida e causar-lhes problemas psicológicos, emocionais e dificultar seu pleno desenvolvimento (Andrade, 2017). Ao longo da coleta de dados, foi notória a mudança de expressão dos rostos das PcD quando começavam a relembrar de episódios de violência sofridos, o que desvela os impactos negativos desta em suas vidas.

Nesta direção, os familiares das PcD relataram situações difíceis e constrangedoras que vivenciadas por conta do preconceito. Muitos sentiram necessidade de afastar a PcD do ambiente escolar, pois além da escola não estar preparada para lidar com a dificuldade de aprendizado apresentada por alguns, os colegas colocavam apelidos, excluíam e até mesmo os agrediam fisicamente por conta das suas limitações. Além disso, percebem o preconceito de outras pessoas ao conviver em sociedade.

A violência contra a PcD se manifesta sob diferentes formas, como: violência institucional e estrutural do Estado quando não garante os direitos assegurados na Constituição e legislação; violência familiar manifestada pela negligência, maus tratos físicos, psicológicos, exploração sexual e financeira; violência pela falta desinformação em relação as leis que asseguram e protegem seus direitos; violência perpetrada pela omissão de profissionais que não notificam ou denunciam a violência; e violência social pelo não reconhecimento da PcD como sujeito de direito (Maior, \& Gugel, 2009).

Em decorrência do constrangimento e preconceito vivenciados, toda a organização familiar se altera, restringindo a participação familiar na sociedade em igualdade com as demais, privando-as de atividades que poderiam oportunizar a inclusão e convivência social. Para os familiares, a maior dificuldade encontrada na sociedade é inclusão e aceitação das PcD. Nesse sentido, identifica-se que as $\mathrm{PcD}$ que vivem no meio rural e suas famílias vivem em um contexto permeado pelo preconceito, pelo convívio social restrito e por espaços de lazer limitados.

Os familiares das PcD relataram adaptações diárias em seu estilo de vida para participar do processo de cuidado e reabilitação do seu familiar, para protegê-lo e favorecer sua inserção na sociedade. Para isso, vivenciam restrições e, muitas vezes, foram levadas a deixar o seu trabalho para cuidar da PcD. Além das dificuldades econômicas devido à perda do emprego, enfrentam desafios pela falta de conhecimento e de orientação sobre os cuidados a serem dispensados a seu familiar, o que causa ansiedade, estresse e culpa.

Embora os participantes vivenciassem situações de violência psicológica diariamente, sendo rejeitados, excluídos e humilhados, muitas vezes esta não era reconhecida como uma forma de violência. As $\mathrm{PcD}$, por vezes, apenas reconheciam a violência quando havia uso de força física, como nos casos de violência física ou sexual. Por esse motivo, quando o assunto violência era mencionado, a reação imediata era de negação, afirmando que no cenário rural essa não existia, sendo algo distante e que comumente ouviam falar na televisão, em grandes centros. Isso corrobora com o não reconhecimento da violência no dia-a-dia das pessoas que residem no cenário rural, reforçando a sua invisibilidade (Hirt, Costa, Arboit, Leite, Hesler, \& Silva, 2017).

A violência sexual também esteve muito presente nos relatos das PcD, comumente ocorrendo no contexto rural, em especial, no ambiente doméstico, sendo perpetrada pela figura masculina. No convívio domiciliar das famílias rurais o homem tende a possuir certo domínio sobre os demais membros da família, devido a características culturais e históricas que o colocam em uma posição superior em relação aos demais membros do grupo familiar. Essa posição hierárquica superior acaba tornando as PcD mais vulneráveis a vivenciar situações de violência pelo homem no espaço doméstico. Neste espaço, considerado seguro, o agressor se aproveita da PcD, especialmente daquela com deficiência intelectual, de sua dificuldade para discernir essas situações abusivas, da dificuldade de verbalização e do próprio medo. Considera-se que o autor da violência contra a PcD está sempre em situação de poder em relação à vítima, ancorando-se em sua autoridade (Maior, \& Gugel, 2009).

Os participantes relataram que não buscaram ajuda em nenhum serviço de atendimento quando foram vítimas de qualquer tipo de violência. Em certos casos somente conversaram com algum familiar próximo para sentirem-se melhores, ou 
até mesmo, acabavam não falando nada e passando por esse momento difícil sozinhos. No Brasil, embora tenham ocorrido avanços no que se refere a ampliação do acesso aos cuidados de saúde, os usuários que residem no cenário rural ainda enfrentam desafios de acesso a serviços que garantam a resolutividade da atenção, especialmente quando possuem agravos a saúde de natureza complexa (Oliveira, et al., 2020), a exemplo das PcD.

Tendo em vista as singularidades dos desafios enfrentados pelas PcD, a Política Nacional de Saúde da Pessoa com Deficiência aponta como algumas de suas diretrizes a promoção da qualidade de vida, atenção integral à saúde, a organização dos serviços e capacitação dos profissionais de saúde (Brasil, 2010).

Dentre os cenários de atenção a saúde as $\mathrm{PcD}$ e aquelas residentes em cenário rural tem-se a Atenção Primária em Saúde (APS), serviço presente em quase todos as cidades brasileiras. Este inclui ações de promoção, prevenção, proteção, diagnóstico, tratamento e reabilitação da saúde, desenvolvidas por equipe multiprofissional (Brasil, 2017).

Embora se tenha uma ampla cobertura da APS no Brasil, com mais da metade da população assistida por equipes de ESF, persistem desigualdades de acesso e oferta de cuidados para as populações residentes nos cenários rurais, sendo um dos grandes desafios da ESF proporcionar uma atenção pautada na integralidade (Oliveira, et al., 2020). Sabe-se que em áreas rurais as Unidades de Saúde da Família diferentemente do que ocorre no cenário urbano, abrem apenas em alguns dias da semana mediante um cronograma singular (Oliveira, et al., 2020). Ou seja, o atendimento nestas unidades é pontual e restrito. E assim, há uma grande dependência de serviços concentrados no cenário urbano.

No âmbito das equipes de ESF, destaca-se o Agente Comunitário de Saúde (ACS). Este profissional tem como atribuições, dentre outras, a realização de visitas domiciliares nas quais realiza o cadastramento das famílias, acompanhamento das condições de saúde, orientações quanto aos serviços de saúde e desenvolvimento de intervenções que visam à promoção da saúde e prevenção de agravos (Barreto et al., 2018). O ACS desenvolve ainda ações objetivando a integração entre a equipe de saúde e a população adscrita a unidade de ESF (Brasil, 2017).

Nesta direção, considerando a atenção a saúde de PcD que residem no cenário rural, o ACS é um dos profissionais que promove a articulação entre essa população e os serviços de saúde, devendo para tanto, conhecer a realidade dessa população (Zeni, Costa, Silva, Honnef, Arboit, \& Colomé, 2020). Este é o profissional que está mais próximo das PcD e de suas famílias residentes no meio rural, criando vínculo e podendo identificar situações de agravos a vida e a saúde, como as situações de violência.

Para o desenvolvimento do estudo, as pesquisadoras contaram com o apoio dos ACSs para identificar as PcD residentes em seus territórios de atuação. Contudo, ao realizar tal solicitação, as pesquisadoras identificaram dificuldades destes profissionais no reconhecimento dos tipos de deficiência. Assim, a equipe de pesquisadoras promoveu um momento de sensibilização para os ACS acerca dos tipos de deficiência, para posteriormente dar continuidades neste levantamento.

Tal situação faz refletir sobre a premência de capacitação profissional acerca dos tipos de deficiência e das implicações para a saúde, pois reconhecer e identificar estas é fator primordial para desenvolver ações de cuidado e acionar demais membros da equipe e outros serviços para assistir a esta população.

\section{Considerações Finais}

A experiência de desenvolver um estudo com pessoas com deficiência residentes em cenário rural auxiliou na compreensão da magnitude do fenômeno da violência e permitiu a percepção da relevância de estudar seus impactos junto a diferentes populações e cenários. Ainda, trouxe à tona a urgência de um olhar diferenciado no que tange as pessoas com deficiência que vivem em cenários rurais no sentido de proporcionar a atenção integral a saúde dessa população que vive em um contexto singular. 
Esta experiência permitiu desvelar os desafios vivenciados pelas PcD que vivem em cenário rural e suas famílias no que se refere as dificuldades financeiras, distância geográfica e acesso aos serviços. Ainda, possibilitou identificar as diferentes formas de violência vivenciadas pelas PcD residentes neste contexto, desde violência física, sexual, até violência psicológica e exclusão social. Diante das barreiras vivenciadas e da invisibilidade desta população, faz-se necessário desenvolver mais investigações que considerem a dupla vulnerabilidade: ser pessoa com deficiência e residir no cenário rural.

Espera-se que esse relato possa contribuir com subsídios para dar maior visibilidade as PcD do cenário rural, diante das dificuldades e agravos por estas vivenciados. Que estes subsídios sejam úteis para a prática clínica dos profissionais de saúde e para os formuladores de políticas públicas, buscando a melhoria da qualidade de vida das pessoas com deficiência e de seus familiares, sobretudo dos que vivem no contexto rural. Ademais, que sirva de estímulo para outros pesquisadores da área da saúde adentrarem no campo da pesquisa no cenário rural, o qual ainda é pouco explorado.

\section{Referências}

Andrade, L. D. (2017). Pessoas com deficiência no Brasil e as diversas formas de violência a que são submetidas. Revista Conversas \& Controvérsias, 4(2):62-76.

Arboit, J., Costa, M. C., Silva, E. B., Colomé, I. C. S., \& Prestes, M. (2018). Violência doméstica contra mulheres rurais: práticas de cuidado desenvolvidas por agentes comunitários de saúde. Saúde e Sociedade, 27(2), 506-517.

Barreto I. C. H. C., Pessoa, V. M., Sousa, M. F. A., Nuto, S. A. S., Freitas, R. W. J. F., Ribeiro, K. G., Vieira-Meyer, A. P. G. F., \& Andrade, L. O. M. (2018). Complexidade e potencialidade do trabalho dos Agentes Comunitários de Saúde no Brasil contemporâneo. Saúde em Debate, 42(spe 1), 114-129.

Brasil. (1988). Constituição da República Federativa do Brasil. Senado.

Brasil. (1990). Lei nº 8.080, de 19 de setembro de 1990. Dispõe sobre as condições para a promoção, proteção e recuperação da saúde, a organização e o funcionamento dos serviços correspondentes e dá outras providências. Diário Oficial da União; 1990; 19 set.

Brasil. (1993). Lei n ${ }^{\circ}$ 8.742, de 7 de setembro de 1993. Dispõe sobre a organização da Assistência Social e dá outras providên cias. Diário Oficial da União; 1993; 8 dez.

Brasil. (1999). Decreto $\mathrm{n}^{\circ} 3.298$, de 20 de dezembro de 1999. Regulamenta a Lei $\mathrm{n}^{\circ} 7.853$, de 24 de outubro de 1989 . Dispõe sobre a Política Nacional para a Integração da Pessoa Portadora de Deficiência, consolida as normas de proteção, e dá outras providências. Diário Oficial da União; $1999 ; 20$ dez.

Brasil. (2009). Decreto $n^{\circ}$ 6.949, de 25 de agosto de 2009. Promulga a Convenção Internacional sobre os Direitos das Pessoas com Deficiência e seu protocolo facultativo, assinados em Nova York, em 30 de março de 2007. Brasília, DF: Presidência da República.

Brasil. (2010). Secretaria de Atenção à Saúde. Departamento de Ações Programáticas Estratégicas. Política nacional de saúde da pessoa com deficiência. Brasília (DF): Ministério da Saúde.

Brasil. (2017). Portaria n ${ }^{\circ}$ 2.436, de 21 de setembro de 2017. Aprova a Política Nacional de Atenção Básica, estabelecendo a revisão de diretrizes para a organização da Atenção Básica, no âmbito do Sistema Único de Saúde (SUS). Diário Oficial da União; $2017 ; 21$ set.

Costa, M. C., \& Lopes, M. J. M. (2012). Elementos de integralidade nas práticas profissionais de saúde a mulheres rurais vítimas de violência. Revista da Escola de Enfermagem da USP, 46(5), 1088-1095.

Dammeyer, J., \& Chapman M. (2018). A national survey on violence and discrimination among people with disabilities. BMC Public Health, 18 , 355.

Douthit, N., Kiv, S., Dwolatzky, T., \& Biswas, S. (2015). Exposing some important barriers to health care access in the rural USA. Public Health, 129(6), 611620 .

Hirt, M. C., Costa, M. C., Arboit, J., Leite, M. T., Hesler, L. Z., \& Silva, E. B. (2017). Social representations of violence against women for a group of rural elderly. Revista Gaúcha de Enfermagem, 38(4), e68209.

Maior, I. G., Gugel, M. A. (2009). Violência contra a Pessoa com Deficiência é o Avesso dos Direitos Consagrados nas Leis e na Convenção da ONU. $6^{\circ}$ Fórum Senado Debate Brasil. Brasília.

Mangundu, M., Roets, L., \& van Rensberg, E. J. (2020). Accessibility of healthcare in rural Zimbabwe: the perspective of nurses and healthcare users. African Journal of Primary Health Care \& Family Medicine, 12(1), 1-7.

Minayo, M. C. S., Souza, E. R., Silva, M. M. A., \& Assis, S. G. (2018). Institutionalizing the theme of violence within Brazil's national health system: progress and challenges. Ciência \& Saúde Coletiva, 23(6), 2007-2016.

Oliveira, A. R., Sousa, Y. G., Silva, D. M., Alves, J. P., Diniz, I. V. A., Medeiros, S. M., Martiniano, C. S., \& Alves, M. A. (2020). Atenção Primária à Saúde no contexto rural: visão de enfermeiros. Revista Gaúcha de Enfermagem, 41, e20190328.

Paviani, J. (2016). Conceitos e formas de violência. In M. R. Modena (Org.), Conceitos e formas de violência (p. 8-20). Educs. 
Research, Society and Development, v. 10, n. 2, e59610213095, 2021

(CC BY 4.0) | ISSN 2525-3409 | DOI: http://dx.doi.org/10.33448/rsd-v10i2.13095

Souza, L. T.; Ireland, T. D. (2020). Políticas educacionais para as pessoas com deficiência: uma análise com base em documentos nacionais e internacionais. Research, Society and Development, 9(1), e144911824.

Tonini, H., \& Lopes, M. J. M. (2017). Desenvolvimento, cuidado e vulnerabilidade: pessoas com deficiência em áreas rurais do RS. Revista Interdisciplinar, $10(3), 110-124$

Ursine, B. L., Pereira, E. L., \& Carneiro, F. F. (2018). Saúde da pessoa com deficiência que vive no campo: o que dizem os trabalhadores da Atenção Básica? Interface - Comunicação, Saúde, Educação, 22(64), 109-120.

World Health Organization (WHO). (2002). World report on violence and healt. Geneva: WHO. 372 p.

World Health Organization (WHO). (2011). World report on disability. Geneva: WHO. 350 p.

Zeni, D., Costa, M. C., Silva, E. B., Honnef, F., Arboit, J., \& Colomé, I. C. S. (2020). Health care for people with disabilities in a rural setting under the perspective of community agents. Revista Brasileira de Enfermagem, 73(6), e20190204. 